Article

\title{
Accounting for the Ecological Footprint of Materials in Consumer Goods at the Urban Scale
}

\author{
Meidad Kissinger ${ }^{1, *}$, Cornelia Sussman ${ }^{2}$, Jennie Moore ${ }^{2}$ and William E. Rees ${ }^{2}$ \\ 1 Department of Geography and Environmental Development, Ben-Gurion University of the Negev, \\ Beer-Sheva, 8410501, Israel \\ 2 School of Community and Regional Planning, University of British Columbia, Vancouver, \\ V6T 1Z2, Canada
}

* Author to whom correspondence should be addressed; E-Mail: meidadk@bgu.ac.il; Tel.: +972-8-6472-002; Fax: +972-8-6472-821.

Received: 6 February 2013; in revised form: 13 April 2013 / Accepted: 26 April 2013 /

Published: 2 May 2013

\begin{abstract}
Ecological footprint analysis (EFA) can be used by cities to account for their on-going demands on global renewable resources. To date, EFA has not been fully implemented as an urban policy and planning tool in part due to limitations of local data availability. In this paper we focus on the material consumption component of the urban ecological footprint and identify the 'component, solid waste life cycle assessment approach' as one that overcomes data limitations by using data many cities regularly collect: municipal, solid waste composition data which serves as a proxy for material consumption. The approach requires energy use and/or carbon dioxide emissions data from process LCA studies as well as agricultural and forest land data for calculation of a material's ecological footprint conversion value. We reviewed the process LCA literature for twelve materials commonly consumed in cities and determined ecological footprint conversion values for each. We found a limited number of original LCA studies but were able to generate a range of values for each material. Our set of values highlights the importance for cities to identify both the quantities consumed and per unit production impacts of a material. Some materials like textiles and aluminum have high ecological footprints but make up relatively smaller proportions of urban waste streams than products like paper and diapers. Local government use of the solid waste LCA approach helps to clearly identify the ecological loads associated with the waste they manage on behalf of their residents. This direct connection can be used to communicate to citizens about
\end{abstract}


stewardship, recycling and ecologically responsible consumption choices that contribute to urban sustainability.

Keywords: urban sustainability; ecological footprint analysis; life cycle assessment; material consumption; waste management

\section{Introduction}

Residents of urban centers in high-income countries consume vast resources and generate immense volumes of waste to maintain their lifestyles [1,2]. Their levels of resource use and waste production make urban centers major contributors to global ecological change: increasing atmospheric carbon, global depletion of renewable and non-renewable resources, and ecological systems overload [3-7]. Many local governments are engaging in efforts to monitor and reduce these impacts, for example, using the ICLEI-Local Governments for Sustainability GHG Emissions Analysis Protocol [8] to measure their contributions to global greenhouse gas (GHG) emissions. While indeed such measurement is critical [9], we suggest that a comprehensive account of urban demands on global renewable resources and ecosystems is equally warranted. Urban ecological footprint analysis (EFA) aims to account for the full scope of energy and materials appropriated by a city's residents, businesses and operations; its biophysical inputs (i.e., various types of biologically productive land); and the carbon dioxide emissions produced as wastes. Indeed several cities have been engaged in measuring the size of their ecological footprints and using the ecological footprint as a policy communication tool: stressing the need for dramatic reform of urban based consumption and waste production toward ecologically sustainable levels. However, data requirements, including limited city-scale data, have prevented EFA from being fully employed as a local planning and monitoring tool $[10,11]$.

In this paper we focus on one critical part of a city's ecological footprint, the material consumption component (i.e., materials consumed through purchase of products by city residents, local businesses and city operations). This component has been calculated to make up between $8 \%$ and $20 \%$ of some urban ecological footprints (e.g., [11-15]). Other major components of any urban footprint include: food consumption, use of electricity and natural gas, transportation, and water. The 'component, solid waste life cycle assessment approach' is an EFA approach that overcomes some data limitations by using data many cities regularly collect: municipal solid waste data which serves as a proxy for material consumption. The logic behind the approach is that most materials in consumer goods end up in the waste stream (either for disposal or recycling), some in a matter of minutes after consumption, others after a few years. Therefore, municipal waste reflects the quantities and types of materials consumed by a local population over a one-year period [12,16-18]. The approach can only be used by cities with access to municipal solid waste data. .Many cities in industrialized countries manage and report on municipal solid waste while cities in industrializing countries often do not. Our set of EF values for material types could still be useful for cities to identify the relative impacts of different materials.

In the component solid waste LCA approach, once material consumption types and quantities have been identified from the solid waste stream data, the ecological footprint for each material is calculated with energy use and $\mathrm{CO}_{2}$ emissions data from process LCA studies. 
Use of the approach could be made easier for local governments and planners with access to ecological footprint conversion factors (or EF values) for individual materials. The initial calculation would be a measure of biologically productive land required (in global hectares) required to produce one unit of the material. For a city to determine the size of the ecological footprint of its consumption of material x, per unit (gha) would be multiplied by the total units of consumption for one year.

To this end, we conducted a thorough review of LCA studies to develop a set of EF values for twelve materials commonly found in urban solid waste streams. We were able to generate a range of values for each material that reflects various production modes, production locations and study methods. These values should be seen as provisional given the small number of original process LCA studies available (Our review yielded 69 studies for 12 materials). Our set of EF values highlights the relative sizes of ecological footprints among materials and indicates that cities monitoring and planning for reductions in material consumption should be aware of both the quantity and ecological impact per unit of individual materials.

\subsection{The Ecological Footprints of Cities}

From a biophysical perspective, cities are wholly dependent upon productive/assimilative land and waterscapes. High-income cities typically have eco-footprints several hundred times larger than their political or geographic footprints. As major consumers of resources and generators of waste, urban populations in these high-income cities are mainly responsible for humanity's current state of ecological overshoot [1,2]. Detailing the urban footprint is essential for sustainability planning. It helps to identify the major points of leverage for policies to reduce urban throughput of resources and production of wastes. It also helps to develop urban systems that contribute to the integrity of the ecosystems upon which cities depend.

EFA quantifies the biophysical 'load' that any specified population (or industrial process) imposes on its supportive ecosystems. The method uses data on energy and material consumption, waste generation (measured as carbon dioxide) and ecosystem productivity to estimate the total ecosystem area (in terms of global average hectares [gha]) required on a continuous basis to produce the resources consumed by the study population, and to assimilate its carbon emissions [19-21]. EFA can thus explicitly connect people's consumption, product by product, to several types of appropriated ecosystem areas, and reveal the gap (positive or negative) between local demand and global supply of bio-capacity.

\subsection{Ecological Footprint Analysis at the City Scale}

To date, two main approaches have been developed to calculate ecological footprints at the sub-national scale: (i) the compound, (ii) the component. The compound approach uses national per capita ecological footprint data, and scales it to the city as much as possible, to reflect, for example, local energy sources. The advantage of this approach is that reliable national level data is more often available than city scale data. However, a footprint based on national level data is limited in its ability to reflect the impacts of local policy and action [10]. Within the component method, the dominant approach is to use economy-wide input-output analysis. We refer to this approach henceforth as the input-output sub-national approach. The input-output sub-national approach uses both local and 
national level data. It takes data on local expenditures (measured in units of national currency such as dollars) for some consumption items like food and materials, and relates them to carbon emissions in an extension of conventional monetary input-output analysis. This data is then combined with national ecological footprint assessment data. An alternative approach is to collect data directly from local government sources without relying on dollars as a proxy for consumption. We call this the direct approach. Because it relies on locally generated energy and materials flow data, this approach can reflect local changes in specific resource consumption and waste generation. For local policy makers and planners, this distinction is critical. They must be able to craft policies and actions that target local conditions, and to monitor and assess the effectiveness of these policies and actions over time. These requirements are not effectively met by EFA approaches based on national level data that are subsequently scaled to the city nor by input-output analysis that uses dollars as a proxy for actual consumption $[13,16,22,23]$. The direct component approach aims to use mostly local data. Local data are collected on specific components of the community/city under study, for example, transportation, buildings, food, consumables and waste. It determines the ecological footprint of each and sums them to generate an overall urban ecological footprint [16,17,24]. Because the footprint is based on local data, the impact of local policy initiatives or actions can be measured over time with successive ecological footprint analyses. Cities often have access to or collect their own data on transportation use (e.g., average vehicle kilometers travelled by urban residents), and buildings (e.g., building types, their energy use and efficiency), which are required for the component analysis. More challenging to come by are data on personal consumption including food and material goods that are not derived from monetary expenditure statistics. This is where the 'component, solid waste LCA approach' is useful. It can be used to identify types and estimate quantities of materials consumed within a city over a specified period of time.

Cities that use the direct component approach will have information to communicate to urban residents and businesses about opportunities for reducing their footprints through wise consumption choices and conservation habits. Changes in consumption are critical to reforming cities toward biophysical sustainability. Material footprint information can be used to develop policy targeted toward strategic supply chain and product stewardship initiatives that avoid high-impact materials. It can support the development or expansion of local recycling and re-use programs, and encourage local businesses and institutions to identify ways their operations can reduce use of high impact materials through use of labeling and promotion of low-impact products. It can also identify when levels of material consumption exceed global ecological carrying capacity and inform how demand management efforts can curb escalating materials throughput in the urban metabolism.

\subsection{The Component Solid Waste Approach}

The 'component, solid waste LCA approach' to EFA was developed by Simmons et al. [17,18], and has been implemented in several studies (e.g., [11,12,14,16,25]). While cities do not commonly monitor or document their residents' material consumption, many manage and monitor solid waste. Most materials that make up consumer goods will eventually enter the solid waste stream (for disposal or recycling), therefore over the course of a one year period, municipal waste reflects the quantities and types of materials consumed by a local population However, these data likely underestimate total 
amounts of materials consumed since all materials used in the manufacturing process are not reflected in the solid waste stream. Therefore, the approach incorporates lifecycle assessment data to estimate the amount of energy and materials used in the supply chain to manufacture the materials found in the waste stream. Although a small amount of waste may be disposed without use of municipal solid waste facilities, municipal solid waste can reasonably be expected to represent the majority of waste generated within the city by proportion and type.

Cities that monitor and document commercial and household waste composition data generally use the following major categories: metal; glass; plastics; paper; organics; textiles; rubber; and hazardous wastes. Many cities use more detailed categories. For example, paper is broken down into paper, newsprint, and cardboard. Plastics are identified by type (PET; HDPE; PVC and LDPE) and by use such as plastic (film) bags and plastic bottles (e.g., [26-30]). One consumer item that appears in the solid waste stream in high quantities and is commonly reported as a separate item is diapers (nappies). In Canberra, Australia in 2009, diapers made up 4.9\%, by weight, of the residential waste stream [30]. A similar figure has been identified in several Israeli cities and towns [31].

Once material consumption types have been determined from the municipal solid waste stream, the ecological footprint for each is estimated. The calculations for these materials incorporate energy use and carbon emissions data from LCAs of the materials. Process LCA quantifies the diverse material and energy inputs required for the production of particular materials and products as well as various wastes including greenhouse gases $(\mathrm{GHG})$, of which sometimes carbon dioxide $\left(\mathrm{CO}_{2}\right)$ emissions are uniquely distinguished [32-34]. This stage of the approach can be time consuming for local governments because it requires a review of LCA studies and the footprint calculations. Ecological footprinting could be made easier for cities through development of an open source, international database of ecological footprint values for materials. City staff would use their own solid waste data to identify quantities of materials consumed by weight over a given period of time, and look up the ecological footprint value for each material in the database. All data sources and calculations could be transparent and accessible for users to access as well.

A set of ecological footprints of individual materials and processes has been published by Huijbregts et al. [35]. Values in that study are derived from the Swiss ecoinvent database. In absence of an open source, international database, that source ecological footprint values could be a starting point for cities. However, it [35] relies heavily on European process LCA data. A dataset of ecological footprint values for materials should reflect production practices around the world including China, a major manufactured goods exporter. Therefore, in our review of process based LCA studies, we included some of the studies that support that dataset [35], but also searched explicitly for studies from Asia, North America, South and Latin America and Australia. In calculating the ecological footprint, Huijbregts et al. [35] separate the energy component into carbon sequestration lands and demand on ecosystems from nuclear energy sources; this separation is no longer standard [36].

Another approach to measuring the EF of material consumption has been proposed by Herva et al. [37]. This approach aims to account for hazardous and toxic wastes that have been combusted with thermal plasma technology. Herva et al. suggest the EF approach is more suitable for industry than for municipal policy makers.

The solid waste LCA approach has limitations that arise from reliance on process LCA studies. While some standardization of method exists, LCA specialists regularly highlight the many 
assumptions required for LCA, and the limitations to comparison of results between studies [38]. As more material LCA studies are published under increasingly standardized conditions, confidence in results of the solid waste LCA based approach will increase.

\section{Methods}

To identify materials commonly consumed in cities, and for which we would determine ecological footprint conversions factors, we reviewed reports on solid waste composition for 10 cities in the UK, the US, Canada, Israel, and Australia (Vancouver (CAN); Edmonton (CAN); Sidney (AUS); Melbourne (AUS); London (UK); York (UK); Edinburgh (UK); Haifa \& Ashdod (ISR); Denver (USA); Seattle (USA). Six material types appeared most often: (1) paper (2) plastics (3) diapers (4) glass (5) metals and (6) textiles. The materials were represented as a percentage of the solid waste streams, by weight, in the following order: paper made up the largest percentage in all cities, ranging from $11.5 \%$ to $27.8 \%$; followed by various types of plastics (ranging from $12.1 \%$ to $16.9 \%$ ). Glass, metals, and textiles were the smallest. Five cities reported on diapers (Vancouver, Canberra, Melbourne, Edinburgh; Haifa), and in each this material was the third largest by weight ranging from $3.1 \%$ in Melbourne to $5.26 \%$ in Vancouver.

From the material types reported by the cities we selected twelve materials: (1) print paper, (2) newsprint, (3) cardboard, (4) PET, (5) HDPE, (6) PVC, (7) PS, (8) glass (9) diapers, (10) cotton textile, (11) aluminum, and (12) steel.

We conducted an extensive review of LCA studies for each material, examining academic literature, and commercial and industrial reports. Each LCA study sets its own boundaries and scale. In order to present comparable footprint and emissions values we made an effort to include studies that used similar parameters, assumptions, and scales. Overall we made an effort to cover cradle to gate data. This means data associated with the manufacturing process from materials extraction to finished product that leaves the factory gate. In the case of plastics most of our values are for plastic polymers owing to lack of available LCA data on finished products. The review yielded 69 relevant studies and included data for European, North American, Asian, and Australian production locations among others. For the complete list of studies see Appendix I. From each LCA study, for each material, we extracted the data on energy sources and $\mathrm{CO}_{2}$ emissions for our calculations of ecological footprint values. While most studied materials are from non-renewable resources (e.g., plastic, metals) and therefore their EF include only energy land (i.e., the area of land for sequestering the carbon dioxide emitted), for materials from renewable resources (e.g., paper, cotton) the study also calculated the crop and forest land required.

\subsection{From LCA to Footprint}

The ecological footprint comprises several types of land including cropland, forest land and energy land [39-41]. The LCA literature review provided us with data on the energy and $\mathrm{CO}_{2}$ emissions associated with each material's life cycle. These data were used for the conversion to ecological footprint. The energy land was calculated for all materials; in the case of materials made from renewable sources, e.g., paper and textiles, the area of forest land (paper) and cropland (textiles) was also calculated. 
Energy land: For calculating the energy land footprint (i.e., the land required to sequester carbon emissions) we used data on the $\mathrm{CO}_{2}$ per tonne of material/product as reported in the LCA studies. We then used a conversion factor of 0.27 hectares of world forest, which is the average area of forest land required to sequester 1 tonne of $\mathrm{CO}_{2}[15,42,43]$. From that, one-third was deducted to reflect the emissions absorbed by the oceans [43]. Finally, an equivalence factor of 1.24 for energy land was applied (Following [15,42]).

Crop land: The cropland footprint has been assessed for cotton textiles. A simplified equation displayed below explains the cropland footprint calculation procedure:

$$
\mathrm{EF}_{(\text {gha })}=(\mathrm{U} / \mathrm{GY}) \times \mathrm{EQF}
$$

where the footprint was calculated by dividing the unit $(\mathrm{U})$ of consumption (1 tonne) by the annual average global yield (GY) [44] and then multiplied by an equivalence factor of 2.39 for cropland [42].

Forest land: To calculate the EF of paper products we integrated several sources. Data on energy inputs and carbon emissions were taken from the LCA papers. The carbon dioxide was then converted to energy land as described above. We then used the UNECE/FAO [45] forest products conversion factors to obtain an average figure for the amount of wood required to produce different types of paper $\left(\mathrm{m}^{3}\right.$ of wood/metric tonne of paper). The next step was to use Global Footprint Network [42] data to convert the equivalent wood weight to the required forest land. The conversion figure used is $1.81 \mathrm{~m}^{3}$ of wood per hectare of forest with global average productive yield. Finally, that area of forest land was multiplied by an equivalence factor of 1.24 [42].

\subsection{Limitations}

Our ecological footprint dataset is limited by the small number of original LCA studies available for each material from international sources. In particular, we found few published LCA studies on materials produced in China. This means that production systems in one of the world's largest exporting nations are under-represented in our set of ecological footprint values. We also found an underwhelming number of studies on some materials, like diapers, that make up a significant component (by weight) of many urban waste streams.

EFA only includes carbon dioxide emissions which, unlike other GHGs, are continually being taken up by natural systems such as forests and oceans. In our review of LCA studies we found that several reported only carbon dioxide equivalent $\left(\mathrm{CO}_{2} \mathrm{e}\right)$ associated with a material's production. $\mathrm{CO}_{2} \mathrm{e}$ includes GHG emissions such as methane and nitrous oxide. Because we had no reliable method for disaggregating the $\mathrm{CO}_{2}$ from $\mathrm{CO} 2 \mathrm{e}$, we could not use these studies. We do include the studies and their $\mathrm{CO}_{2} \mathrm{e}$ data in the Appendix because they represent the findings of our LCA review, and to reveal the scope of available data.

Because our data set is established from published LCA studies and reports, any inherent issues of data quality, system parameters, or calculations, are repeated in our review. We attempted to overcome this limitation by including a range and breadth of LCA studies, and also by presenting the range of EF values rather an average for each material. We restricted our LCA boundaries from cradle to gate. We did not include components such as shipping distances to the city or the footprint of the retailer (this 
would be part of the commercial building footprint component). Therefore, the size of the footprints is likely underestimated.

\section{Results and Discussion}

Table 1 summarizes the ecological footprint values (measured in gha/tonne) that we calculated for the most common materials found in municipal waste streams. The minimum, maximum and mean emissions for each material are shown together with the standard deviation.

Table 1. Ecological footprint of materials.

\begin{tabular}{cccccc}
\hline & N & Min & Max & Average & Standard deviation \\
\hline Sub Category & & gha/tonne & gha/tonne & gha/tonne & gha/tonne \\
Glass & 5 & 0.18 & 0.40 & 0.24 & 0.09 \\
HDPE & 4 & 0.13 & 0.35 & 0.20 & 0.10 \\
PVC & 4 & 0.31 & 0.53 & 0.41 & 0.07 \\
PET & 5 & 0.24 & 0.57 & 0.48 & 0.11 \\
Polystyrene & 5 & 0.26 & 1.04 & 0.66 & 0.25 \\
Steel & 10 & 0.38 & 0.90 & 0.61 & 0.16 \\
Diapers & 2 & 0.94 & 1.34 & 1.14 & 0.28 \\
Newsprint & 6 & 2.15 & 2.34 & 2.23 & 0.08 \\
Cardboard & 3 & 2.71 & 2.79 & 2.76 & 0.04 \\
Printing paper & 12 & 2.62 & 3.23 & 2.82 & 0.17 \\
Aluminum & 5 & 1.77 & 4.06 & 2.42 & 0.75 \\
Cotton fabric & 8 & 8.35 & 12.21 & 10.20 & 1.59 \\
\hline
\end{tabular}

Consolidating the data in a table enables identification of high and low impact material. For example, textiles have the highest ecological footprint per unit of material. This is because of the large area of agricultural land and energy inputs required to grow cotton, as well as high amounts of energy used in the material's production. Paper, cardboard and newsprint also have relatively high ecological footprints due to the land area required to grow trees. The actual footprint values for plastics are likely higher than the values reported here because over half of the data sources available for plastics are for plastic polymers rather than finished products.

Urban policy makers, planners, businesses and residents will want to link these data with their local solid waste data that identifies how much of each material is regularly consumed. Although textiles and aluminum have high ecological footprints, they make up smaller proportions of most urban waste streams than paper products and diapers. Consumption of paper products and diapers might be more important targets for reduction at the urban scale. This level and detail of information is the kind required by policy makers and planners who wish to develop targeted local policies and by local residents, businesses and organizations seeking to reduce their urban ecological footprints.

In our review of LCA studies we found variations in LCA measures from different parts of the world. While these variations can be explained by different LCA methods and data availability, they may also reflect variations in production methods and energy sources used in different parts of the world (e.g., coal based electricity vs. hydroelectric sources). For example, the EF of a ton of aluminum produced in China or in Australia is at least 45\% larger than one tonne of aluminum produced in 
Europe. Publication of more LCA studies is necessary for true comparisons. In a previously published paper [9], we presented the GHG emissions calculated for the same set of materials, using data from the same LCA sources. We believe it is important for cities to have information on both GHG emissions and ecological footprint values to determine (1) sustainable levels of urban material consumption and (2) to inform policies and programs that promote rapid change toward those levels. We compare GHG emissions values with average ecological footprints for the twelve materials in Table 2, arranged in ascending order of size/emissions per tonne.

Table 2. Average ecological footprints and greenhouse gas (GHG) emissions of materials.

\begin{tabular}{cccc}
\hline & Average GHG Emissions & & Average Ecological Footprint \\
\hline Sub Category & $\mathbf{C O}_{\mathbf{2}} \mathbf{e} /$ tonne & Sub Category & gha/tonne \\
\hline Cardboard & 890 & Glass & 0.24 \\
Glass & 990 & HDPE & 0.20 \\
HDPE & 1,015 & PVC & 0.41 \\
Newsprint & 1,120 & PET & 0.48 \\
Printing paper & 1,290 & Steel & 0.61 \\
PVC & 1,920 & Polystyrene & 0.66 \\
PET & 2,240 & Diapers & 1.14 \\
Steel & 2,530 & Newsprint & 2.23 \\
PS & 2,970 & Cardboard & 2.76 \\
Diapers & 3,580 & Printing paper & 2.82 \\
Aluminum & 10,840 & Aluminum & 2.42 \\
Cotton fabric & 21,500 & Cotton fabric & 10.20 \\
\hline
\end{tabular}

Table 2 highlights the differences in environmental impact each measurement tool is designed to assess: GHG emissions inventories account for the GHG emissions related to a material's production, while the ecological footprint accounts for the area of biologically productive land required to produce a material and to assimilate associated production wastes, in perpetuity. The difference is apparent in a comparison of materials. Cotton textile is a high impact material in terms of both ecological footprint and GHG emissions. Cotton textiles require land area on which to grow cotton crops, and textile production is energy intensive. Aluminum has an ecological footprint approximately equal in size to that of newsprint or cardboard. Its GHG emissions, however, are almost ten times higher. In ecological footprint accounting, the tremendous energy requirements of aluminum are registered as 'energy land' (bio-productive land area to sequester carbon dioxide) and make up most of the aluminum footprint. However, paper production impacts more heavily on use and over-use of the earth's bio-productive land area. Paper products are less energy intensive to produce so the 'energy' land component of their ecological footprints is smaller, but the size of their ecological footprints is increased by their requirement for 'forest land' on which to grow trees. Similar to aluminum, the plastics: PET and PS have over twice the GHG emissions of cardboard, newsprint and printing paper. Therefore, production of plastics (per ton) makes a greater contribution to atmospheric carbon levels, yet their ecological footprints are approximately one quarter the size of any paper products.

In our review of the literature, we found few academic studies whose sole aim was to carry out a product or material LCA. More often, the study purpose was to investigate potential improvements in 
production methods or management systems, for example, comparing different textile tailoring scenarios [46], or end of life options for plastic bottles [47]. In these studies boundaries often excluded production of the material itself. Other studies used existing material LCA data, such as those found in ecoinvent. Studies on production processes outside of Europe frequently included ecoinvent LCA data which suggests challenges in obtaining local process data. Our review of Chinese language journals yielded five appropriate studies. In total we found 69 LCA studies that provided data necessary for use in our ecological footprint conversion calculations. The lack of studies aimed directly at assessing life cycle production impacts suggests that promotion of their value for sustainability research and action could be heightened. It also speaks to the challenges posed by high data requirements and the lack of reliable, accessible data, including the barrier of proprietary data related to some industrial processes. We found an increasing number of material LCAs conducted or commissioned by commercial and industrial associations such as the World Aluminum Association and the European Container Glass Federation. Individual companies are also publishing information on the carbon emissions of their products. For these products, the actual LCA studies are not commonly available but in some cases, information such as the study author, reviewer, or LCA protocol is provided. Perhaps more industrybased studies will be conducted as carbon taxes and cap and trade systems are expanded. Consumer pressure for more ecologically benign products may also encourage more reporting.

\section{Conclusions}

With data from the 69 LCA studies, we were able to develop a range of ecological footprint values for each material, reflecting production data from several countries. Our set of EF values incorporates the best currently available LCA data. Given the small number of studies for each material, and from each production location, and the differences in study methods, our values should be viewed as provisional. A greater number of standardized LCA studies using consistent process boundaries will increase accuracy in measuring ecological footprints associated with the twelve materials. Cities accounting for the ecological footprints of their material consumption could follow the EFA convention of selecting the lowest reported value for each material, and up-dating values as LCA data become available. The relative size of ecological footprints (per production unit) among the materials is likely a fair representation and offers cities a general ranking of materials that may be useful in policy and program development.

We believe that the ecological footprint with its comprehensive representation of ecological loads that extend beyond carbon emissions should become as mainstream a local policy and planning tool as GHG emissions inventories have become over the last decade. While climate change is a critical issue for cities to tackle through GHG emissions reduction policy and action, increasing global resource depletion and related ecosystem impacts pose equally imminent and dramatic risks [2,47] EFA reveals that the global human population is using earth's resources more quickly than they can be replenished. In fact, it would take the earth 1.5 years to regenerate the resources consumed and assimilate the wastes produced in 2012 [42]. As discussed, EFA at the urban scale must overcome challenges related to local data availability. The component solid waste LCA approach can overcome this limitation for the material consumption component, for those cities that monitor municipal solid waste. Local government use of the solid waste LCA approach helps to clearly identify the ecological impacts 
associated with the waste they manage on behalf of their residents. This direct connection can be used to communicate to citizens about stewardship, recycling and ecologically responsible consumption choices that contribute to urban sustainability.

\section{Acknowledgments}

The authors would like to thank the Social Science and Humanities Research Council of Canada for grant funding to both William Rees and Jennie Moore in support of this project. We also thank the Foreign Affairs and International Trade Canada (DFAIT) - "Understanding Canada-Canadian Studies Program" fellowship, and to the European Union ERG grant on urban sustainability to Meidad Kissinger. Finally the authors also thank Zoe Wang, for her review of Chinese journals.

\section{Supplementary Materials}

Supplementary materials can be accessed at: http://www.mdpi.com/2071-1050/5/5/1960/s1.

\section{Conflict of Interest}

The authors declare no conflict of interest.

\section{References and Notes}

1. WWF (World Wide Fund for Nature). Living Planet Report; World Wide Fund for Nature: Gland, Switzerland, 2010.

2. WWF (World Wide Fund for Nature). Living Planet Report; World Wide Fund for Nature, Gland, Switzerland, 2012.

3. Alberti, M. Measuring urban sustainability. Environ. Impact Assess. Rev. 1996, 16, 381-424.

4. Rees, W.E. Is sustainable city an oxymoron? Local Environ. 1997, 2, 303-310.

5. Rees, W.E. Getting serious about urban sustainability: Eco-footprints and the vulnerability of $21 \mathrm{st}$ century cities. In Sustainability Science: The Emerging Paradigm and the Urban Environment; Bunting, T., Filion, P., Walker, R., Eds.; Springer: Toronto, Canada, 2010; Chapter 5.

6. Newman, P. The Environmental Impacts of Cities. Environ Urban. 2006, 18, 275-295.

7. Grimm, B.N.; Faeth, H.S.; Golubiewski, E.N.; Redman, L.C.; Wu, J.; Bai, X.; Briggs, M.J. Global change and the ecology of cities. Science 2008, 319, 756-760.

8. Local Governments for Sustainability (ICLEI). International Local Government GHG Emissions Analysis Protocol (IEAP), Version 1.0., 2009. Available online: http://carbonn.org/fileadmin/ user_upload/carbonn/Standards/IEAP_October2010_color.pdf (accessed on 26 April 2013).

9. Kissinger, M.; Sussman, C.; Moore, J.; Rees, W.E. Accounting for GHG of materials at the urban scale-Relating existing process life cycle assessment studies to urban material and waste composition. LCE 2013, in press.

10. Wilson, J.; Grant, J. Calculating ecological footprints at the municipal level: What is a reasonable approach for Canada? Local Environ. 2009, 14, 963-979.

11. Moore, J.; Kissinger, M.; Rees, W.E. An urban metabolism assessment and ecological footprint of metro vancouver. J. Environ. Manage. 2013, 124, 51-61. 
12. Barrett, J.; Vallack, H.; Jones, A.; Haq, G. A Material Flow Analysis and Ecological Footprint of York; Technical Report; Stockholm Environmental Institute: Stockholm, Sweden, 2002.

13. Aall, C.; Norland, I. The Use of the Ecological Footprint in Local Politics and Administration: Results and implications from Norway. Local Environ. 2005, 10, 159-172.

14. Kissinger, M.; Haim, A. Urban Hinterlands: The case of an Israeli town ecological footprint. Environ. Dev. Sustain. 2008, 10, 391-405.

15. Scotti, M.; Bondavalli, C.; Bondini, A. Ecological footprint as a tool for local sustainability: The municipality of Piacenza (Italy) as a case study. Environ. Impact Assess. 2009, 29, 39-50.

16. Chambers, N.; Simmons, C.; Wackernagel, M. Sharing Natures Interest; Earthscan: London, UK, 2000.

17. Simmons, C.; Chambers, N. Footprinting UK households: How big is your ecological garden? Local Environ. 1998, 3, 355-362.

18. Simmons, C.; Lewis, K.; Barrett, J. Two feet-two approaches: A component-based model of ecological footprinting. Ecol. Econ. 2000, 32, 375-380.

19. Rees, W.E. Ecological footprints and appropriated carrying capacity: What urban economics leaves out. Environ. Urban. 1992, 4, 121-130.

20. Rees, W.E.; Wackernagel, M. Ecological footprints and appropriated carrying capacity: measuring the natural capital requirements of human economy. In Investing in Natural Capital: The Ecological Economics Approach to sustainability; Janson, A.M., Hammer, M., Folke, C., Costanza, R., Eds.; Island press: Washington, DC, USA, 1994; pp. 362-390.

21. Wackernagel, M.; Rees, W.E. Our Ecological Footprint-Reducing Human Impact on the Earth; New Society Publishers: Gabriola, BC, Canada, 1996.

22. Curry, R.; Maguire, C.; Simmons, C.; Lewis, K. The use of material flow analysis and the ecological footprint in regional policy-making: Application and insights from Northern Ireland. Local Environ. 2011, 16, 165-179.

23. Wiedmann, T.; Minx, J.; Barrett, J.; Wackernagel, M. Allocating ecological footprints to final consumption categories with input-output analysis. Ecol Econ. 2006, 56, 428-448.

24. Barrett, J. Component ecological footprint: Developing sustainable scenarios. Impact Assess. Proj. Apprais. 2001, 19, 107-118.

25. Gottlieb, D.; Kissinger, M.; Haim, A.; Vigoda, E. Implementing the ecological footprint at the institute level. Ecol Indic. 2011, 18, 91-97.

26. Cascadia Consulting Group. Seattle Public Utilities 2010 residential waste stream composition study final report, 2011. Available online: http://www.seattle.gov/util/Documents/ Reports/SolidWasteReports/CompositionStudies/index.htm/ (accessed on 17 March 2012).

27. City of Edinburgh. The City of Edinburgh Council Edinburgh's waste and recycling strategy 010 2025; City of Edinburgh: Edinburgh, UK, 2010.

28. City of Edmonton. The Edmonton sustainability papers discussion paper 10-Sustainable waste management; City of Edmonton: Edmonton, Canada, 2010.

29. AEA Technology. Greater London Authority Waste Composition Scoping Study; AET/ENV/R/1826; AET Technology: Oxfordshire, UK, 2004. 
30. APC. Kerbside Domestic Waste and Recycling Audit; APC Environmental Management: Sydney, Australia, 2009.

31. IMEP - The Israeli Ministry of Environmental Protection. National solid waste composition survey; The Israeli Ministry of Environmental Protection: Jerusalem, Israel, 2005.

32. Udo de Haes, H.A.; Jolliet, O.; Finnveden, G.; Hauschild, M.; Krewitt, W.; Muller-Wenk, R. Best available practices regarding impact categories and category indi- cators in life cycle impact assessment-Part I. Int. J. Life Cycle Ass. 1999, 4, 66-74.

33. Halberg, N.; Weidema, B. Life Cycle Assessment in the Agrifood Sector. 2004. Available online: http://www.lcafood.dk/lca conf/ (accessed on 12 June 2011).

34. Berg, S.; Lindholm, E. Energy use and environmental impacts of forest operations in Sweden. J. Clean Prod. 2005, 13, 33-42.

35. Huijbregts, M.; Hellweg, S.; Frischknecht, R.; Hungerbuhler, K.; Hendriks, A. Ecological footprint accounting in the life cycle assessment of products. Ecol. Econ. 2008, 64, 798-807.

36. Global Footprint Network. Ecological Footprint Standards 2009; Global Footprint Network: Oakland, CA, USA, 2009.

37. Herva, M.; Hernando, R.; Carrasco, E.; Roca, E. Development of a methodology to assess the footprint of wastes. J. Hazard Mater. 2010, 180, 264-273.

38. Boustead, I. Eco-profiles of the European Plastics Industry: Low Density Polyethylene; PlasticsEurope: Brussels, Belgium, 2005.

39. Galli, A.; Kitzes, J.; Wermer, P.; Wackernagel, M.; Niccolucci, V.; Tiezzi, E. An Exploration of the mathematics behind the ecological footprint. In Ecodynamics: The Prigogine Legacy; Brebbia, C., Ed.; Wit Press: Billerica, MA, USA, 2007; pp. 249-256.

40. Wackernagel, M.; Monfreda, C.; Schulz, N.; Erb, K.; Haberl, H.; Krausmann, F. Calculating national and global ecological footprint time series: resolving conceptual challenges. Land Use Policy. 2004, 21, 271-278.

41. Kitzes, J.; Peller, A.; Goldfinger, S.; Wackernagel, M. Current methods for calculating national ecological footprint accounts. Sci. Environ. Sust. Soc. 2007, 4, 1-9.

42. Global Footprint Network. Footprint Basics Overview, 2012. Available online: http://www.footprintnetwork.org/en/index.php/GFN/page/footprint_basics_overview/ (accessed on 22 August 2012).

43. Monfreda, C.; Wackernagel, M.; Deumling, D. Establishing national natural capital accounts based on detailed ecological footprint and biological capacity assessments. Land Use Policy 2004, 21, 231-246.

44. FAO (United Nations Food and Agriculture Organization). FAOSTAT: Production: Crops 2010. Available online: http://faostat.fao.org/site/567/DesktopDefault.aspx/ (accessed on 2 May 2012).

45. UNECE/FAO. Forest Product Conversion Factors for the UNECE Region. Timber section: Geneve, Switzerland, 2009

46. Herva, M.; Franco, A.; Ferreiro, S.; Alvarez, A.; Roca, E. An approach for the application of the ecological footprint as environmental indicator in the textile sector. J. Hazard Mater. 2008, 156, $478-487$. 
47. Millennium Ecosystem Assessment. Ecosystems and Human Well-being: Synthesis; Island Press: Washington, DC, USA, 2005. Available online: http://www.maweb (accessed on 7 May 2012).

(C) 2013 by the authors; licensee MDPI, Basel, Switzerland. This article is an open access article distributed under the terms and conditions of the Creative Commons Attribution license (http://creativecommons.org/licenses/by/3.0/). 